\title{
Changes in air pollution and childhood respiratory viral infections in Korea post-COVID-19 outbreak
}

\section{To the editor}

Since the initial outbreak of coronavirus disease 2019 (COVID19), global lockdowns have been implemented, resulting in a decline in overall human activities, including economies, industries, and lifestyles. The government of South Korea enforced an executive order on public health measures, such as social distancing and compulsory mask-wearing. The ambient air pollution, a global health burden for several decades, seems to have improved worldwide compared to the prepandemic period. ${ }^{1)}$ The global health status also underwent significant changes after the COVID19 outbreak, such as fewer hospital visits and decreased respiratory tract infection rates. ${ }^{2,3)}$ The present study aimed to observe the changes in air pollution levels and the number of respiratory viral infections among hospitalized children in South Korea before versus after the COVID-19 pandemic, especially after implementation of the public health measures.

The government of South Korea organized the COVID-19 Central Disaster and Safety Countermeasures Headquarters comprising experts from various organizations and implemented nationwide social distancing measures on March 22, 2020. They released basic guidelines for maintaining distance in daily life to prevent viral penetration into individual living spaces, removing conditions favorable for pathogen transmission and survival, minimizing the excretion of the virus from the body, and blocking the pathogen's transmission. ${ }^{4)}$ They classified 4 levels of social distancing and announced them on a regular basis. Additionally, online office work and school work and gathering restrictions resulted in decreased traffic and activity volumes.

Daily mean concentrations of air pollutants (particulate matter $[\mathrm{PM}]_{2.5}, \mathrm{PM}_{10}$, ozone $\left[\mathrm{O}_{3}\right]$, nitrogen dioxide $\left[\mathrm{NO}_{2}\right]$, carbon monoxide [CO], and sulfur dioxide [ $\left.\mathrm{SO}_{2}\right]$ ) in 5 metropolitan cities (Seoul, Daejeon, Daegu, Gwangju, and Busan) were gathered to represent the national data of South Korea. Data on ambient air pollution were measured and recorded by air pollutant observatory stations in each city under NAMIS (National Ambient Air Quality Monitoring Information System) surveillance. Data on national air quality were accessed through the AIRKOREA website provided by the Korea Ministry of Environment and the Korea Environment Corporation.5) Since air quality in South Korea traditionally exhibited relatively poor levels in winter and spring under the influence of Asian fine dust, we designated the study period from February 1 to May 31 each year. $\left.{ }^{6}\right)$

Weekly respiratory virus data provided by the Korea Disease
Control and Prevention Agency were collected from February to May annually in 2015-2021.7) A total of 125,463 cases of respiratory viruses from hospitalized children were collected from the Korea Disease Control and Prevention Agency during the study period: 42,279 cases of rhinovirus, 20,602 cases of metapneumovirus, 16,361 cases of adenovirus, 15,537 cases of parainfluenza virus, 12,585 cases of bocavirus, 10,181 cases of respiratory syncytial virus, and 7,918 cases of coronavirus.

We observed decreasing trends in ambient $\mathrm{NO}_{2}, \mathrm{PM}_{2.5}, \mathrm{PM}_{10}$, and $\mathrm{SO}_{2}$ levels in 2020 since the beginning of the pandemic and following lockdowns compared to the same periods before the pandemic (Fig. 1). Since industrial emissions and traffic contribute largely to these air pollutants, noticeable decreases were observed after the implementation of the lockdowns. However, the levels of $\mathrm{CO}$ and $\mathrm{O}_{3}$ did not show significant changes compared to those in previous years. A marked reduction of ambient $\mathrm{NO}_{2}$ and paradoxical increase of ambient $\mathrm{O}_{3}$ levels at urban stations during the pandemic were also observed abroad, such as in Brazil, China, and Europe. ${ }^{8)}$ Increased O3 levels during lockdowns may be attributed to a reduction in NOx emissions, which leads to lower $\mathrm{O}_{3}$ titration, since its formation depends on the ratio of nonmethane hydrocarbons, nitrogen oxides, and volatile organic compounds in the atmosphere. ${ }^{8)}$ In 2021, when social distancing between individuals persisted while most industries in South Korea and nearby countries such as China and India resumed, several parameters including $\mathrm{PM}_{2.5}, \mathrm{PM}_{10}, \mathrm{SO}_{2}$, and $\mathrm{O}_{3}$ exhibited slight increases compared to those in 2020 (Fig. 1). A steep increase in ambient $\mathrm{PM}_{10}$ seems to have resulted from several sandstorms that began and spread from the Eastern Gobi desert steppe during March 2021.9)

Respiratory viral infections in the childhood population showed a dramatic decrease after the COVID-19 outbreak since public health measures were implemented (Fig. 2). The average number of respiratory virus detections from February to May each year before the pandemic was 23,120, but in 2020 and 2021, only 5,563 and 4,298 cases were detected, showing reductions of $75.9 \%$ and $81.4 \%$, respectively. Several studies from abroad also demonstrated decreased trends in respiratory viruses and hospital use. A reduction in pediatric asthma encounters and decreased steroid prescriptions were observed, probably due to decreased rhinovirus infections during the pandemic. ${ }^{3)}$ In addition, the global decline in influenza virus circulation was concurrent with the pandemic, and most other respiratory viruses exhibited de- 

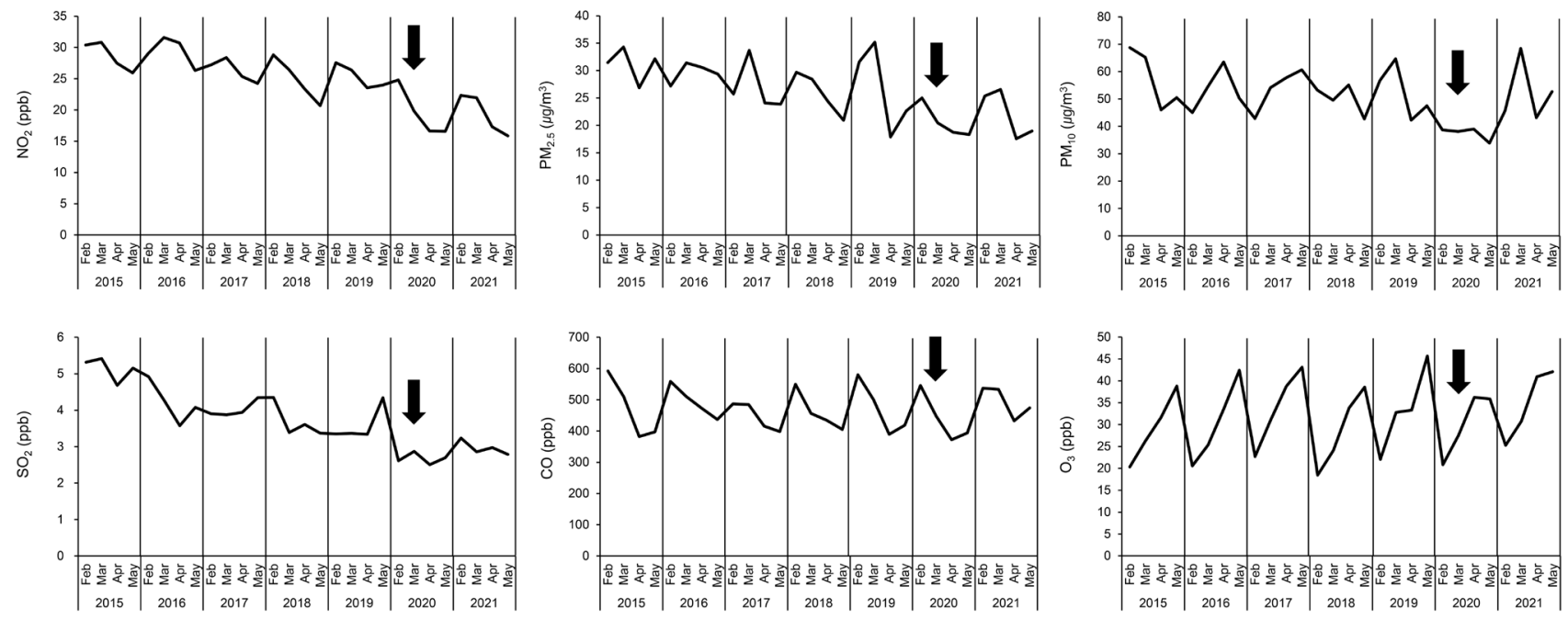

Fig. 1. Trends of monthly mean levels of each air pollutant from February to May annually in 2015-2021 in 5 metropolitan cities of South Korea. The black arrow represents the starting point of the coronavirus disease 2019 lockdown and social distancing in South Korea.

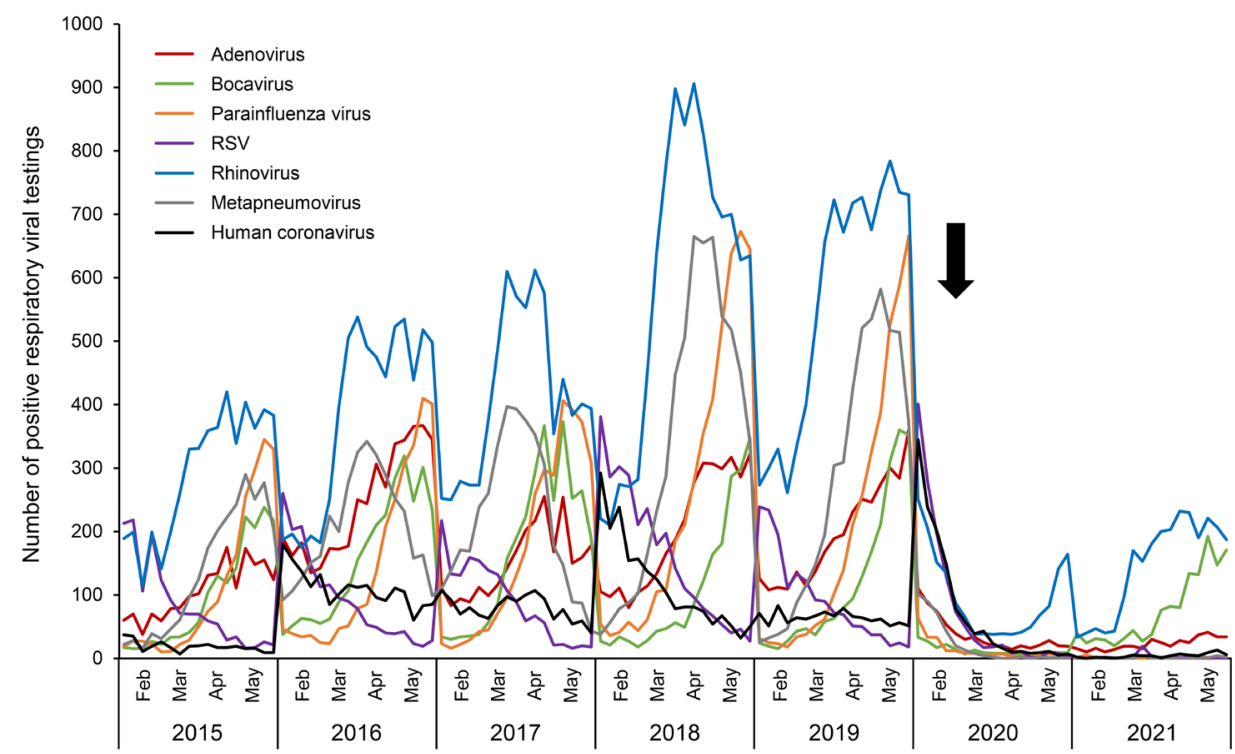

Fig. 2. Changes in numbers of respiratory viruses detected in hospitalized children from February to May annually in 2015-2021 in South Korea. The black arrow represents the starting point of the coronavirus disease 2019 lockdown and social distancing in South Korea. RSV, respiratory syncytial virus.

creased trends in 2020 as well. ${ }^{2,3,10)}$ However, in early 2021 in South Korea, a slight increase in rhinovirus and bocavirus infection was observed, and adenovirus was detected in small numbers. Similar patterns of increasing rhinovirus and adenovirus detection in early 2021 were also found abroad. ${ }^{10)}$ The exact causes of different patterns of viral circulation after COVID-19 remain unclear. In addition to relaxed COVID-19 health measures and the expansion of offline schools, viral factors such as types of transmission mechanism or survival time on the surface due to structural differences may contribute to different circulating patterns. ${ }^{10)}$

This study has a few limitations. First, we were unable to estimate the prevalence of respiratory viral infections among hospitalized patients because of the lack of total sample numbers. Second, we could not analyze the effect of air pollution on respiratory viral infections, as mandatory mask wearing and social distancing may have been confounding variables. In addition, we could not gather regional information on viral data from the website.

In conclusion, nationwide social distancing and public health measures implemented by the South Korean government since the COVID-19 outbreak resulted in both improved ambient air pollution levels and decreased respiratory viral infection rates. Further studies of the relationship between air pollution and viral transmission are needed to establish a national policy to improve the health status of the childhood population and improve air quality. 
Hyung Kyu Park, Jung Yeon Shim, MD, PhD

Department of Pediatrics, Kangbuk Samsung Hospital, Sungkyunkwan University School of Medicine, Seoul, Korea

Corresponding author: Jung Yeon Shim, MD, PhD

Department of Pediatrics, Kangbuk Samsung Hospital, Sungkyunkwan University School of Medicine, 29 Saemunanro, Jongno-gu, Seoul 03181, Korea

凶Email: jy7.shim@samsung.com

https://orcid.org/0000-0001-9367-2233

\section{Footnotes}

Conflicts of interest: No potential conflict of interest relevant to this article was reported.

Funding: This study received no specific grant from any funding agency in the public, commercial, or not-for-profit sectors.

ORCID:

Hyung Kyu Park (1) https://orcid.org/0000-0003-3102-8308

Jung Yeon Shim @ https://orcid.org/0000-0001-9367-2233

\section{References}

1. Wang M, Liu F, Zheng M. Air quality improvement from COVID-19 lockdown: evidence from China. Air Qual Atmos Health 2021;14:591604.
2. Olsen SJ, Azziz-Baumgartner E, Budd AP, Brammer L, Sullivan S, Pineda $\mathrm{RF}$, et al. Decreased influenza activity during the COVID-19 pandemic United States, Australia, Chile, and South Africa, 2020. MMWR Morb Mortal Wkly Rep 2020;69:1305-9.

3. Taquechel K, Diwadkar AR, Sayed S, Dudley JW, Grundmeier RW, Kenyon CC, et al. Pediatric asthma health care utilization, viral testing, and air pollution changes during the COVID-19 pandemic. J Allergy Clin Immunol Pract 2020;8:3378-87.e11.

4. Korea Ministry of Health and Welfare. COVID-19 [Internet]. Sejong (Korea): Ministry of Health and Welfare; [cited 2021 Jan 15]. Available from: https://ncov.mohw.go.kr/en/.

5. Air Korea. Air pollution data Incheon [Internet]. Incheon (Korea): Korea Environment Corporation; 2020 [cited 2020 Dec 24]. Available from: http://www.airkorea.or.kr/web/pastSearch?pMENU_NO=123.

6. Kim HC, Kim E, Bae C, Cho JH, Kim BU, Kim S. Regional contributions to particulate matter concentration in the Seoul metropolitan area, South Korea: seasonal variation and sensitivity to meteorology and emissions inventory. Atmos Chem Phys 2017;17:10315-32.

7. Infectious Disease Portal. Acute respiratory infection data [Internet]. Cheongju (Korea): Korea Disease Control and Prevention Agency; 2021 [cited 2021 Oct 10]. Available from: http://www.kdca.go.kr/npt/biz/npp/ iss/ariStatisticsMain.do.

8. Sicard P, De Marco A, Agathokleous E, Feng Z, Xu X, Paoletti E, et al. Amplified ozone pollution in cities during the COVID-19 lockdown. Sci Total Environ 2020;735:139542.

9. Filonchyk M. Characteristics of the severe March 2021 Gobi Desert dust storm and its impact on air pollution in China. Chemosphere 2021;287:132219.

10. Olsen SJ, Winn AK, Budd AP, Prill MM, Steel J, Midgley CM, et al. Changes in influenza and other respiratory virus activity during the COVID-19 pandemic - United States, 2020-2021. MMWR Morb Mortal Wkly Rep 2021;70:1013-9.

How to cite this article: Park HK, Shim JY. Changes in air pollution and childhood respiratory viral infections in Korea post-COVID-19 outbreak. Clin Exp Pediatr 2022;65:211-3. https://doi.org/10.3345/cep.2021.01585 